\title{
Air pollution and cognition
}

\author{
Another reason to cut air pollution and record the health benefits likely to follow
}

\section{Chris J Griffiths professor of primary care ${ }^{1}$, lan S Mudway senior lecturer in respiratory toxicology ${ }^{2}$}

${ }^{1}$ Barts Institute of Population Health Sciences, Queen Mary University of London, London, UK ; ${ }^{2}$ MRC-PHE Centre in Environment and Health, King's College London, London, UK

It is almost 20 years since leaded petrol was banned in the UK to protect children's brains from its damaging effects-a move forced on the delaying UK government by a European directive from Brussels. Other components of traffic related air pollution, including carbon monoxide and polycyclic aromatic hydrocarbons, have also been shown to be neurotoxic, ${ }^{12}$ and increasing numbers of studies support the view that poor air quality can have adverse effects on the brain, from suboptimal cognitive development in children ${ }^{3}$ to accelerated cognitive decline in adults. ${ }^{45}$

In Barcelona, children attending primary schools in high pollution areas had slower rates of cognitive development compared with those attending schools in low pollution areas. ${ }^{3}$ In adults in China, long term exposure to air pollution has been linked to worse cognitive performance in verbal and maths tests. $^{6}$

As with all new scientific observations, uncertainties remain (specifically, on the underlying causal mechanisms and critical exposure windows), as well as challenging inconsistencies. We have better evidence on cognitive development in children than on cognitive decline among older people, for example, ${ }^{7}$ although the evidence linking incident dementia with long term exposure to air pollution seems increasingly robust, as study findings are replicated. ${ }^{8}$

A recent cohort analysis of 140000 people registered with 75 London general practices, found a significant association between exposure to higher pollution levels and a diagnosis of dementia. ${ }^{4}$ Adults living in the highest quintile of nitrogen dioxide $\left(\mathrm{NO}_{2}\right)$ exposure had a $40 \%$ higher risk of dementia than those in the lowest quintile. In the highest quintile, exposure equated to an annual mean concentration of $>41 \mu \mathrm{g} / \mathrm{m}^{3} \mathrm{NO}_{2}$, a level commonly found in London and many other UK towns and cities, largely because of a high density of diesel vehicles.

\section{Causal pathways}

Mechanistically, there are substantial gaps in our knowledge, though established associations between ischaemic stroke and short term exposure to gaseous and particulate air pollution ${ }^{9}$ provide a possible causal pathway for vascular dementia. Tantalisingly, combustion derived particulates have been found in postmortem brain samples, ${ }^{10}$ and early molecular and histopathological features of Alzheimer's disease have been identified in children and young adults living in polluted cities in Mexico. ${ }^{11} 12$

Particulate matter (soot, largely from diesel engines) has also recently been observed in macrophages in the placentas of women living in London, ${ }^{13}$ suggesting a mechanism for a link with low birth weight ${ }^{14}$ and reduced head circumference at birth. $^{15}$

Evidence of adverse effects of traffic related air pollution over the life course continues to grow, as succinctly summarised in the report by the Royal College of Physicians' working party in 2016. ${ }^{16}$ The report recommended urgent action to reduce air pollution and improve health. Persuasive recent data on cognition and cognitive development add impetus to that recommendation.

\section{Evidence to support pollution measures}

Government and local authorities need to take bold action to reduce traffic related air pollution, especially in highly populated urban areas, and researchers should exploit such policy initiatives when they arise, to evaluate the effectiveness of these actions. Researchers leading the influential California Children's Health Study, for example, showed that poor air quality was associated with slower growth in lung function in adolescents, ${ }^{17}$ and went on to show that, as air quality improved after public health measures, lung growth also improved. Their approach ${ }^{18}$ strengthened the evidence for both the adverse effects of air pollution and the benefits of intervention.

As the first World Health Organization conference on air pollution and health ends in Geneva, and the UK Health Alliance on Climate Change publishes a new report calling for more urgent action, ${ }^{19}$ it's time to cut pollution and measure the effects. The introduction of London's ultra low emission zone next year is one example of a bold intervention that gives researchers the opportunity to evaluate the link between air quality and health throughout life-from birth weight, through cognitive development in children and incidence of non-communicable 
diseases such as heart attacks and stroke, to dementia and both disease-specific and all-cause mortality.

The introduction of such schemes is politically challenging. Evidence that they deliver measurable health dividends will improve public confidence and generate support. Here the scientific and medical communities need to tread carefully, staying at arm's length from the politicians but delivering clear objective assessments to guide the development of evidence based public health policies.

At a time when science is often denigrated at home and overseas, the application of the scientific method has never been more important.

Competing interests: We have read and understood BMJ policy on declaration of interests and have no relevant interests to declare.

Provenance and peer review: Commissioned; not externally peer reviewed.

1 Grandjean P, Landrigan PJ. Neurobehavioural effects of developmental toxicity. Lancet Neurol 2014:13:330-8. 10.1016/S1474-4422(13)70278-3 24556010

Perera FP, Li Z, Whyatt R, etal . Prenatal airborne polycyclic aromatic hydrocarbon exposure and child IQ at age 5 years. Pediatrics 2009;124:e195-202. 10.1542/peds.2008-3506. 19620194

3 Sunyer J, Esnaola M, Alvarez-Pedrerol M, etal . Association between traffic-related air pollution in schools and cognitive development in primary school children: a prospective cohort study. PLoS Med 2015;12:e1001792. 10.1371/journal.pmed.1001792 25734425

4 Carey IM, Anderson HR, Atkinson RW, etal . Are noise and air pollution related to the incidence of dementia? A cohort study in London, England. BMJ Open 2018;8:e022404. 10.1136/bmjopen-2018-022404. 30206085

5 Chen $\mathrm{H}$, Kwong JC, Copes R, etal . Living near major roads and the incidence of dementia, Parkinson's disease, and multiple sclerosis: a population-based cohort study. Lancet 2017:389:718-26. 10.1016/S0140-6736(16)32399-6 28063597

6 Zhang $X$, Chen $X$, Zhang $X$. The impact of exposure to air pollution on cognitive performance. Proc Natl Acad Sci U S A 2018;115:9193-7. 10.1073/pnas.1809474115 30150383
7 Cullen B, Newby D, Lee D, etal . Cross-sectional and longitudinal analyses of outdoor air pollution exposure and cognitive function in UK Biobank. Sci Rep 2018;8:12089. 10.1038/s41598-018-30568-6 30108252

8 Chen $\mathrm{H}$, Kwong JC, Copes R, etal . Exposure to ambient air pollution and the incidence of dementia: a population-based cohort study. Environ Int 2017;108:271-7. 10.1016/j.envint.2017.08.020 28917207

9 Shah ASV, Lee KK, McAllister DA, etal . Short term exposure to air pollution and stroke: systematic review and meta-analysis. BMJ 2015;350:h1295. 10.1136/bmj.h1295. 25810496

10 Maher BA, Ahmed IAM, Karloukovski V, etal . Magnetite pollution nanoparticles in the human brain. Proc Natl Acad Sci U S A 2016;113:10797-801. 10.1073/pnas.1605941113. 27601646

11 González-Maciel A, Reynoso-Robles R, Torres-Jardón R, Mukherjee PS, Calderón-Garcidueñas L. Combustion-derived nanoparticles in key brain target cells and organelles in young urbanites: culprit hidden in plain sight in Alzheimer's disease development. J Alzheimers Dis 2017;59:189-208. 10.3233/JAD-170012 28598844

12 Calderón-Garcidueñas L, González-Maciel A, Reynoso-Robles R, etal . Alzheimer's disease and alpha-synuclein pathology in the olfactory bulbs of infants, children, teens and adults $\leq 40$ years in Metropolitan Mexico City. APOE 4 carriers at higher risk of suicide accelerate their olfactory bulb pathology. Environ Res 2018;166:348-62. 10.1016/.j.envres.2018.06.027 29935448

13 Liu NM, Miyashita L, Mcphail G, Thangaratinam S, Grigg J. Do inhaled carbonaceous particles translocate from the lung to the placenta? Eur Respir J 2018;52(suppl 62):PA360.

14 Smith RB, Fecht D, Gulliver J, etal . Impact of London's road traffic air and noise pollution on birth weight: retrospective population based cohort study. BMJ 2017;359:j5299. 10.1136/bmj.j5299. 29208602

15 Pedersen M, Giorgis-Allemand L, Bernard C, etal . Ambient air pollution and low birthweight: a European cohort study (ESCAPE). Lancet Respir Med 2013;1:695-704. 10.1016/S2213-2600(13)70192-9 24429273

16 Royal_College_of_Physicians. Every breath we take: the lifelong impact of air pollution RCP, 2016.

17 Gauderman WJ, Vora H, McConnell R, etal . Effect of exposure to traffic on lung development from 10 to 18 years of age: a cohort study. Lancet 2007;369:571-7. 10.1016/S0140-6736(07)60037-3 17307103

18 Gauderman WJ, Urman R, Avol E, etal . Association of improved air quality with lung development in children. N Engl J Med 2015;372:905-13. 10.1056/NEJMoa1414123. 25738666

19 UK Health Alliance on Climate Change. Moving beyond the air quality crisis. UKHACC 2018. http://www.ukhealthalliance.org/wp-content/uploads/2018/10/Moving-beyond-theAir-Quality-Crisis-4WEB-29_10-2018-final-1.pdf

Published by the BMJ Publishing Group Limited. For permission to use (where not already granted under a licence) please go to http://group.bmj.com/group/rights-licensing/ permissions 